\title{
Antimicrobial Efficacy of Cinnamonum verum Essential Oil Alone and in Combination with Antibiotics and Other Essential Oils
}

\author{
Hemali Padalia, Tejas Rathod, Pooja Moteriya and Sumitra Chanda*
}

Phytochemical, Pharmacological and Microbiological Laboratory, Department of Biosciences

(UGC-CAS), Saurashtra University, Rajkot, 360 005, Gujarat, India

*Corresponding author

\author{
A B S T R A C T
}

Microbial resistance to antibiotics is a global health problem. Infectious diseases are increasing day by day for various untackable reasons. Thus, there is an urgent need to develop novel antimicrobial agents from natural substances such as plants which are easily

Keywords

Cinnamonum verum,

Essential oil,

Antibiotics,

Synergistic

antimicrobial activity.

Article Info

Accepted:

26 September 2017

Available Online:

10 November 2017 available with no toxic effects which are generally associated with synthetic drugs. Besides there is every chance of getting a new drug or lead to drug molecule because of the vast diversity which they possess. The present study was designed to examine synergistic antimicrobial activity of Cinnamon (Cinnamonum verum) oil with some commercial antibiotics and some other essential oils against a panel of multidrug resistant microorganisms. The composition of Cinnamon oil was characterized by GC-MS analysis, the principal compound identified was cinnamaldehyde $(62.28 \%)$ and benzyl alcohol $(24.60 \%)$. Combination of Cinnamon oil with antibiotics and other essential oils showed synergistic antimicrobial activity by disc diffusion method. Microbes which showed significant sensitivity were further assayed with various concentrations of the potent combination of Cinnamon oil in a broth dilution method and determined by fractional inhibitory concentration ( $\sum$ FIC) index. Among the different combinations, Cinnamon oil with ampicillin and Cinnamon oil with Clove oil was found to be most effective combination against pathogenic microorganisms. Synergistic potential of Cinnamon oil can be a new and important way for the treatment of infectious diseases.

\section{Introduction}

The emergence of drug resistant pathogens has becomes one of the most severe threats against the treatment of infectious diseases and significant global economic and healthcare crisis (Huttner et al., 2013). Lifethreatening infections caused by bacteria and fungi are the serious problem in agricultural, food, water and medical tradition. Furthermore, the treatments of infectious disease by conventional antimicrobial agents are not acceptable because they cause resistance over a time and have an undesirables side effect (Ibrahim et al., 2012).

This has led to an increased thrust towards identification of novel antimicrobial agents from the natural sources. The use of plant based herbal medicine for health care is known since ancient times. Plants are rich source of active phytoconstituents which can be used for curing various diseases (Nakhuru et al., 2013; Padalia and Chanda, 2015). 
One of the most promising active constituent of plants for development of novel antimicrobial agents is essential oil. Essential oils are yield of secondary metabolism of aromatic plants and mixture of diverse volatile compounds (Pinto et al., 2013). Essential oils are generally extracted from plant by steam or hydro distillation methods and they are mixture of wide range of compound mainly terpenoids particularly monoterpenes and sesquiterpenes and a variety of low molecular weight aliphatic hydrocarbons (Dorman and Deans, 2000). Essential oils and their components have many applications in food flavouring and preservation, traditional medicine as well as in cosmetic and pharmaceutical industries (Gendy et al., 2015).

Essential oils have broad spectrum of activity including antibacterial, antifungal, antiviral, antimycotic and insecticidal against wide range of microorganisms like bacteria, fungi, virus, yeast etc. (Akthar et al., 2014; Ghabraie et al., 2016; Luis et al., 2016). To improve the effectiveness of antimicrobial agents, their combined use with the essential oils is one of the promising approach (Giordani et al., 2004). Essential oil is mixture of number of complex phytoconstituents which have individual biological effects. The effects of compounds depend on their concentration when they are used alone or in combination. Interactions between antimicrobial agents may lead to additive, synergistic or antagonistic effects (Bakkali et al., 2008).

Some essential oils such as cinnamon, eucalyptus, lavender, lemon, lime, mint, rosemary, basil, clove and neem are traditionally used by people in different parts of the world. Cinnamon oil is derived from Cinnamonum verum (Lauraceae family) and is generally used as spices. It is therapeutically used in neuralgia, headache, diarrhea and to treat problems of the digestive system. It is also used in the treatment of cancer and many diseases associated with microorganisms (Prabuseenivasan et al., 2006; Clemente et al., 2016). The aim of the present investigation was to evaluate synergistic potential of cinnamon essential oil. The synergistic potential was evaluated with some commercial antibiotics and some other essential oils against multidrug resistant microorganisms.

\section{Materials and Methods}

\section{Plant material}

Different essential oils viz. cinnamon (Cinnamomum verum) $(\mathrm{CN})$, clove (Syzygium aromaticum) (CL), orange (Citrus reticulata) (OR), lemon (Citrus lemon) (LE), karanja (Pongamia pinnata) (KJ) and neem (Azadirachta indica) (NE) were purchased from the Yucca Enterprise, Mumbai, India.

\section{Synergistic antimicrobial activity}

Synergistic antimicrobial activity of cinnamon oil was done by disk diffusion method against Gram positive bacteria, Gram negative bacteria and fungal strains.

\section{Microorganisms tested}

The microorganisms were obtained from National Chemical Laboratory, Pune, India. The microorganisms were maintained at $4{ }^{\circ} \mathrm{C}$. The Gram-positive bacteria studied were Bacillus cereus (BC) ATCC11778, Bacillus subtilis (BS) ATCC6633, Staphylococcus aureus (SA) ATCC29737, Corynebacterium rubrum (CR) ATCC14898. The Gramnegative bacteria were Escherichia coli (EC) NCIM2931, Pseudomonas aeruginosa (PA) ATCC9027, Klebsiella pneumoniae (KP) NCIM2719 and Salmonella typhimurium (ST) ATCC23564. The fungi studied were Candida glabrata NCIM3448, Candida 
albicans ATCC2091, Cryptococcus neoformans ATCC34664, Candida epicola (CE) NCIM3367.

\section{Antibiotics used in this study}

Antibiotic used in the study Ampicillin (AP), Gentamicin (GEN), Chloramphenicol (CH), Penicillin-G (P), Tetracycline (TE), Amphotericin B (AMP), Clotrimazole (CC), Ketoconazole (KT), Fluconazole (FLC), Nystatin (NYS), Itraconazole (IT). All antibiotics were purchased from Hi-Media Laboratory Pvt. Ltd., Mumbai, India.

\section{Disk diffusion assay}

Synergistic antimicrobial activity of cinnamon oil with antibiotics (AP, CH, GEN, $\mathrm{P}$, TE, AMP, CC, FLC, KT, IT and NYS) and other essential oils (CL, OR, LE, KJ and NE) was assessed against Gram positive bacteria, Gram negative bacteria and fungi by using agar disc diffusion method (Rakholiya and Chanda, 2012). The petri plates were prepared by pouring $20 \mathrm{ml}$ of sterilized molten Mueller Hinton Agar (MHA) for bacteria and $20 \mathrm{ml}$ Sabouraud dextrose agar for fungi, seeded with $200 \mu \mathrm{l}$ test culture containing $1 \times 10^{8} \mathrm{cfu} / \mathrm{ml}$ as McFarland 0.5 turbidity standard. Plates were allowed to solidify.

Standard antibiotics paper discs $(6 \mathrm{~mm})$ were impregnated with $20 \mu$ l of cinnamon oil (20\% in ethanol) separately. The sterile paper discs were impregnated with $20 \mu \mathrm{l}$ combination of cinnamon oil (20\% in ethanol) with other essential oil (20\% in ethanol) and allowed to saturate for $30 \mathrm{~min}$ and were placed on the surface of the agar plates which had previously been inoculated with tested microorganisms.

All the plates were incubated for $24 \mathrm{~h}$ at 37 ${ }^{\circ} \mathrm{C}$ for bacteria and $48 \mathrm{~h} 28{ }^{\circ} \mathrm{C}$ for fungi. Results were recorded by measuring the zone of inhibition appearing around the discs. All the tests were performed in triplicate and the mean values are presented.

\section{Determination of minimum inhibitory concentration (MIC) and minimum bactericidal concentration (MBC)}

To determine MIC of six essential oils and nine antibiotics, the broth micro-dilution method was performed (Edziri et al., 2012) with some modifications against bacteria and fungi. The inoculums of the test bacteria were prepared using the colony suspension method (EUCAST, 2003). Ninety-six-well culture plates (Tarsons Products Pvt. Ltd.) were used, and serial two-fold dilutions of essential oil (200-6.25 $\mu \mathrm{l} / \mathrm{ml}$ ) were dispensed into the plate wells. Two-fold dilutions of all antibiotics $(32-1 \mu \mathrm{g} / \mathrm{ml})$ were used. The volume of dispensed drug was $20 \mu \mathrm{l}$ per well along with $150 \mu 1$ of Mueller Hinton Broth. $30 \mu 1$ of bacterial culture at a density of $6 \times 10^{5} \mathrm{CFU} / \mathrm{ml}$ was added to the wells. Three control wells were maintained for each test batch; the positive control (antibiotic, Mueller-Hinton broth and test organism) and sterility control (Mueller-Hinton broth and ethanol) and negative control (Mueller-Hinton broth, test organism and ethanol).The plates were incubated for $24 \mathrm{~h}$ at $37^{\circ} \mathrm{C}$ for bacteria and $48 \mathrm{~h}$ at $28^{\circ} \mathrm{C}$ for fungi. The bacterial activity in the test wells were detected by adding $40 \mu \mathrm{l}$ of $0.2 \mathrm{mg} / \mathrm{ml}$ of 2-(4-Iodo phenyl)-3-(4-nitro phenyl)5-phenyltetrazolium chloride (I.N.T.) (Himedia, India) solution dissolved in sterile distilled water to each well (Frey and Meyers, 2011). The plates were incubated for further $30 \mathrm{~min}$. After addition of INT, inhibition of bacterial growth was visible as a clear well and presence of growth was detected by presence of pink red color (Singh et al., 2010). The lowest concentration (highest dilution) of the essential oil and antibiotics required to inhibit visible growth of the tested microorganism was designated as its MIC. 
For determination of minimum bactericidal concentration (MBC), wells showing no growth as well as from the lowest concentration showing growth in the MIC assay for all the samples were chosen. Bacterial cells from the MIC test plates were sub-cultured on freshly prepared solid nutrient agar by making streaks on the surface of the agar. The plates were incubated for $24 \mathrm{~h}$ at 37 ${ }^{\circ} \mathrm{C}$ for bacteria and $48 \mathrm{~h}$ at $28{ }^{\circ} \mathrm{C}$ for fungi. Plates that did not show growth was considered to be the MBC for the drug used (Akinyemi et al., 2005).

Determination of combinations of
cinnamon oil with antibiotics/other
essential oil

Synergistic antimicrobial activity of the cinnamon oil with antibiotics and other essential oils was assessed against Gram positive bacteria, Gram negative bacteria and fungi. All combinations were mixed at a ratio of 1:1 and were tested for MICs which were determined by micro well dilution method as described above.

The fractional inhibitory concentration ( $\sum$ FIC) index was calculated by adding the FIC values of antimicrobial compounds $\left(\mathrm{FIC}_{\mathrm{A}}+\mathrm{FIC}_{\mathrm{B}}\right)$. The $\mathrm{FIC}_{\mathrm{A}}$ and $\mathrm{FIC}_{\mathrm{B}}$ values represent the lowest concentration of oil and antibiotics/extracts respectively that caused the inhibition of bacterial growth in the combination tests. Each of the combination was calculated according to the following formula: $\sum \mathrm{FICI}=\mathrm{FIC}_{\mathrm{A}}+\mathrm{FIC}_{\mathrm{B}}$

For interpretation of the results, $\leq 0.5$ was assigned as a synergistic effect, $0.5>\sum \mathrm{FIC} \leq$ 0.75 represented as a partial synergy, 0.76 to 1.0 represented as an additive effect, $>1.0$ to 4.0 represented as an indifferent effect and $\sum$ FIC $>4.0$ antagonistic effect between two tested antimicrobial agents (Sabate et al., 2012).

\section{Results and Discussion}

\section{Synergistic antimicrobial activity}

The synergistic antimicrobial activity of cinnamon oil alone, other essential oil alone, commercial antibiotics alone and in combination i.e. their synergistic effect was assessed by measuring their zones of inhibition against various microorganisms.

\section{Antimicrobial activity of cinnamon oil with antibiotics}

The antibacterial activity of cinnamon oil alone, five antibiotics alone (AP, CH, GEN, $P$, and TE) and their synergistic effect against four Gram positive bacteria is given in Fig.1. The essential oil $\mathrm{CN}$ alone showed antibacterial activity against all the four Gram positive bacteria though the level of activity varied. The highest zone of inhibition was against $B$. cereus $(39.5 \mathrm{~mm})$. All the four Gram positive bacteria were susceptible to all the five antibiotics alone except $B$. cereus which was resistant to $\mathrm{AP}$ and $\mathrm{P}$; and $C$. rubrum which was resistant to GEN. The synergistic activity was envisaged almost with all the 5 antibiotics against all the four bacterial strains with different level of inhibitory activity (Fig.1). Cinnamon oil with antibiotic AP showed synergistic antibacterial activity against $S$. aureus and $C$. rubrum (Fig. 1A); while antibiotic $\mathrm{CH}$ showed synergistic activity against $B$. subtilis and $C$. rubrum (Fig. 1B); antibiotic GEN showed synergistic antibacterial activity against $B$. cereus (Fig. 1C); antibiotic $\mathrm{P}$ showed synergistic antibacterial activity against $S$. aureus and $C$. rubrum (Fig. 1D) and antibiotic TE showed synergistic antibacterial activity against $B$. cereus and C. rubrum (Fig. 1E).

The antibacterial activity of cinnamon oil alone, five antibiotics alone (AP, CH, GEN, $\mathrm{P}$, and TE) and their synergistic effect against 
four Gram negative bacteria is given in Fig. 2. The cinnamon oil alone showed antibacterial activity against three Gram negative bacteria (E. coil, P. aeruginosa and S. typhimurium) except $K$. pneumoniae. The highest zone of inhibition was against $E$. coil $(15 \mathrm{~mm})$. E. coil was susceptible to four antibiotics (AP, $\mathrm{CH}$, GEN and TE) but resistant to antibiotic P. $K$. pneumoniae was resistant but $S$. typhimurium was susceptible to all the five antibiotics. $P$. aeruginosa was susceptible to GEN and TE but resistant to the other three antibiotics. The antibiotics AP, GEN and P did not show any synergistic activity against any of the four Gram negative bacteria. Antibiotic $\mathrm{CH}$ and TE showed synergistic activity against E. coil and S. typhimurium (Fig. 2B and 2E).

The cinnamon oil alone showed inhibitory antifungal activity against all the four fungi, though the level of activity varied (Fig. 3). The highest zone of inhibition was against $C$. albicans $(38.5 \mathrm{~mm})$.

All the four fungi were susceptible to all the six antibiotics except $C$. albicans which was resistant to AP and $C$. neoformans which was resistant to FLC. A very slight synergistic activity was envisaged against fungi. Cinnamon oil plus antibiotic AMP and KT showed synergistic activity against only $C$. glabrata (Fig. 3A and 3E).

\section{Antimicrobial activity of cinnamon oil with other essential oils}

The antibacterial activity of cinnamon oil alone, other essential oils alone (CL, KJ, LE, $\mathrm{OR}$ and NE) and their synergistic effect against four Gram positive bacteria is given in Fig.4. CL oil alone showed very slight antibacterial activity against $B$. cereus and $C$. rubrum. The other 4 essential oils (KJ, LE, OR and NE) alone did not show any activity. Cinnamon oil with KJ oil showed synergistic antibacterial activity against $C$. rubrum and $B$. subtilis. None of the oils showed antagonistic effects except OR oil against $S$. aureus (Fig. 4). CL oil alone showed activity against $K$. pneumoniae and $P$. aeruginosa while KJ, LE and NE oils alone showed activity against only KP while OR oil alone did not show any activity. Cinnamon oil with CL, KJ, LE, OR and NE oil showed synergistic antibacterial activity against KP. However, no antagonistic activity was envisaged (Fig. 5). CL oil alone showed slight antifungal activity against all the four fungi. The other KJ, LE, OR and NE essential oils alone did not show any antifungal activity. Five essential oils in combination with cinnamon oil showed antifungal activity against fungi but no synergistic activity was envisaged. However, no antagonistic activity was envisaged (Fig. 6).

The antimicrobial activity of $\mathrm{CN}$ oil alone and its synergistic activity i.e. combination with antibiotics/ other essential oils were investigated which showed varied levels of antimicrobial activity by disc diffusion method. $\mathrm{CN}$ oil with all the five antibiotics (AP, CH, GEN, P, TE) and $\mathrm{CN}$ with $\mathrm{KJ}$ oil showed maximum synergistic antibacterial activity against Gram positive bacteria $C$. rubrum.

$\mathrm{CN}$ oil with antibiotics $\mathrm{CH}$ and $\mathrm{TE}$ also showed synergistic antibacterial activity against E. coli; $\mathrm{CN}$ oil with $\mathrm{OR}$ oil showed synergistic antibacterial activity against $K$. pneumoniae. $\mathrm{CN}$ oil plus antibiotic AMP and KT showed synergistic activity against only C. glabrata.

So, combination of $\mathrm{CN}$ oil with antibiotics/other essential oils were taken up for further study against two Gram positive (C. rubrum and B. subtilis), Gram negative (E. coli and $P$. aeruginosa) bacteria and Fungi (C. albicans and $C$. neoformans) by minimum inhibitory concentration. 
Determination of minimum inhibitory concentration (MIC) and minimum bactericidal concentration (MBC)

MIC and MBC values of essential oil $(\mathrm{CN}$, $\mathrm{CL}, \mathrm{OR}, \mathrm{LE}, \mathrm{NE}$ and $\mathrm{KJ}$ ) and antibiotic (AP, $\mathrm{CH}$, GEN, P, TE, AMP, FLC, KT and NS) were tested for its antimicrobial activity at various concentration against two Gram positive, two Gram negative and two fungi strain. The values are presented in Table 1 and 2 .
For Gram positive bacteria strains, MIC and MBC values of all five antibiotics ranged from 1 to $32 \mu \mathrm{g} / \mathrm{ml}$ and 4 to $>32 \mu \mathrm{g} / \mathrm{ml}$ respectively. B. subtilis was most susceptible bacterial pathogen to GEN and TE (MIC$1 \mu \mathrm{g} / \mathrm{ml})$. C. rubrum was also susceptible bacterial pathogen to GEN and $\mathrm{P}$ (MIC$1 \mu \mathrm{g} / \mathrm{ml})$. The MIC and MBC value of all six essential oil ranged from 12.5 to $200 \mu 1 / \mathrm{ml}$ and 50 to $>200 \mu \mathrm{l} / \mathrm{ml}$ respectively. $B$. subtilis was most susceptible bacterial pathogen to $\mathrm{CL}$ and $\mathrm{LE}$ oil (MIC $-12.5 \mu \mathrm{l} / \mathrm{ml})$.

Fig.1 Synergistic antibacterial activity of cinnamon oil with antibiotics against Gram positive bacteria $(\mathrm{A}=$ Ampicillin, $\mathrm{B}=$ Chloramphenicol, $\mathrm{C}=$ Gentamicin, $\mathrm{D}=$ Penicillin, $\mathrm{E}$ $=$ Tetracycline)
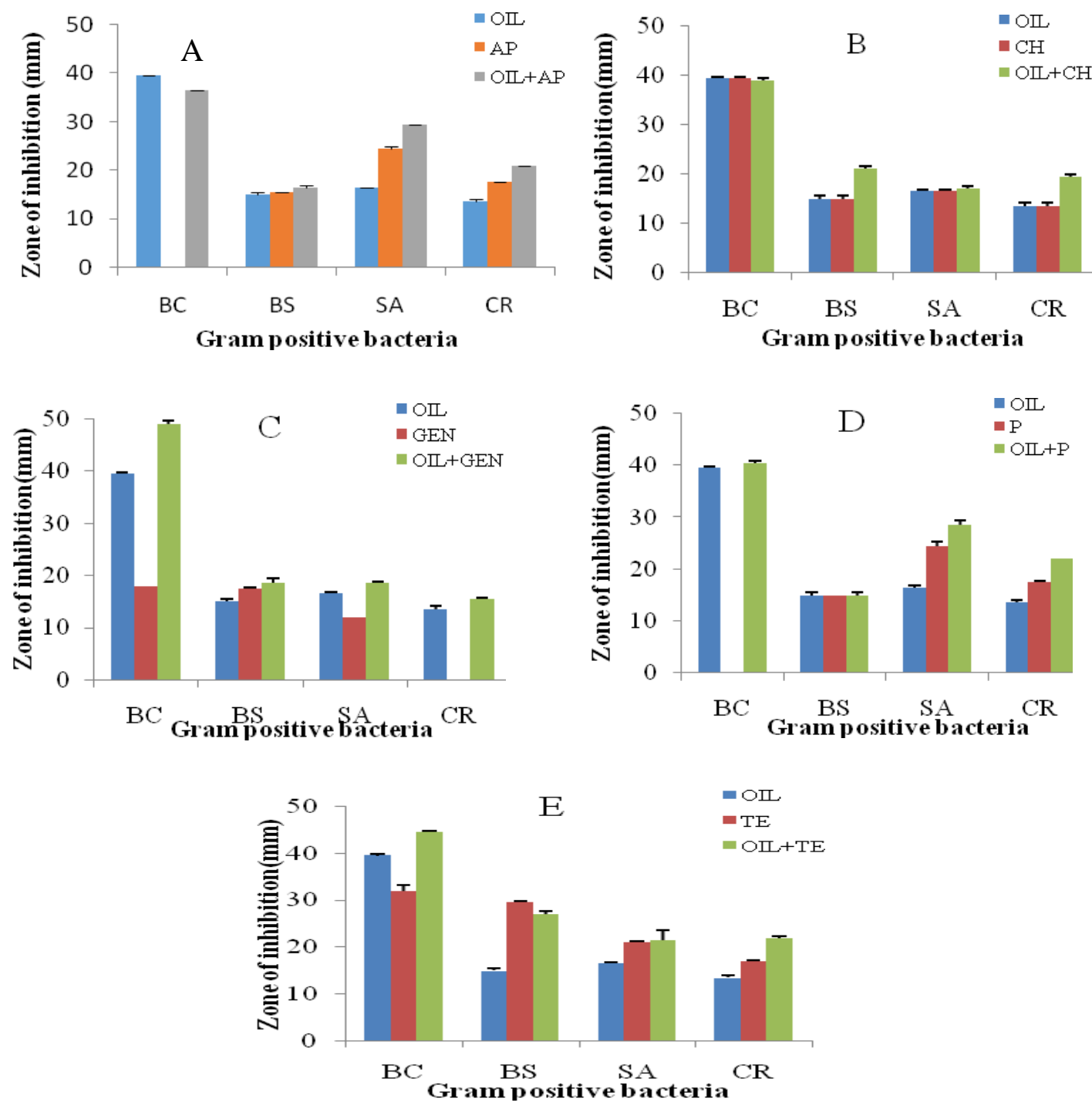
Fig.2 Synergistic antibacterial activity of cinnamon oil with antibiotics against Gram negative bacteria $(\mathrm{A}=$ Ampicillin, $\mathrm{B}=$ Chloramphenicol, $\mathrm{C}=$ Gentamicin, $\mathrm{D}=$ Penicillin, $\mathrm{E}$

$$
\text { =Tetracycline) }
$$
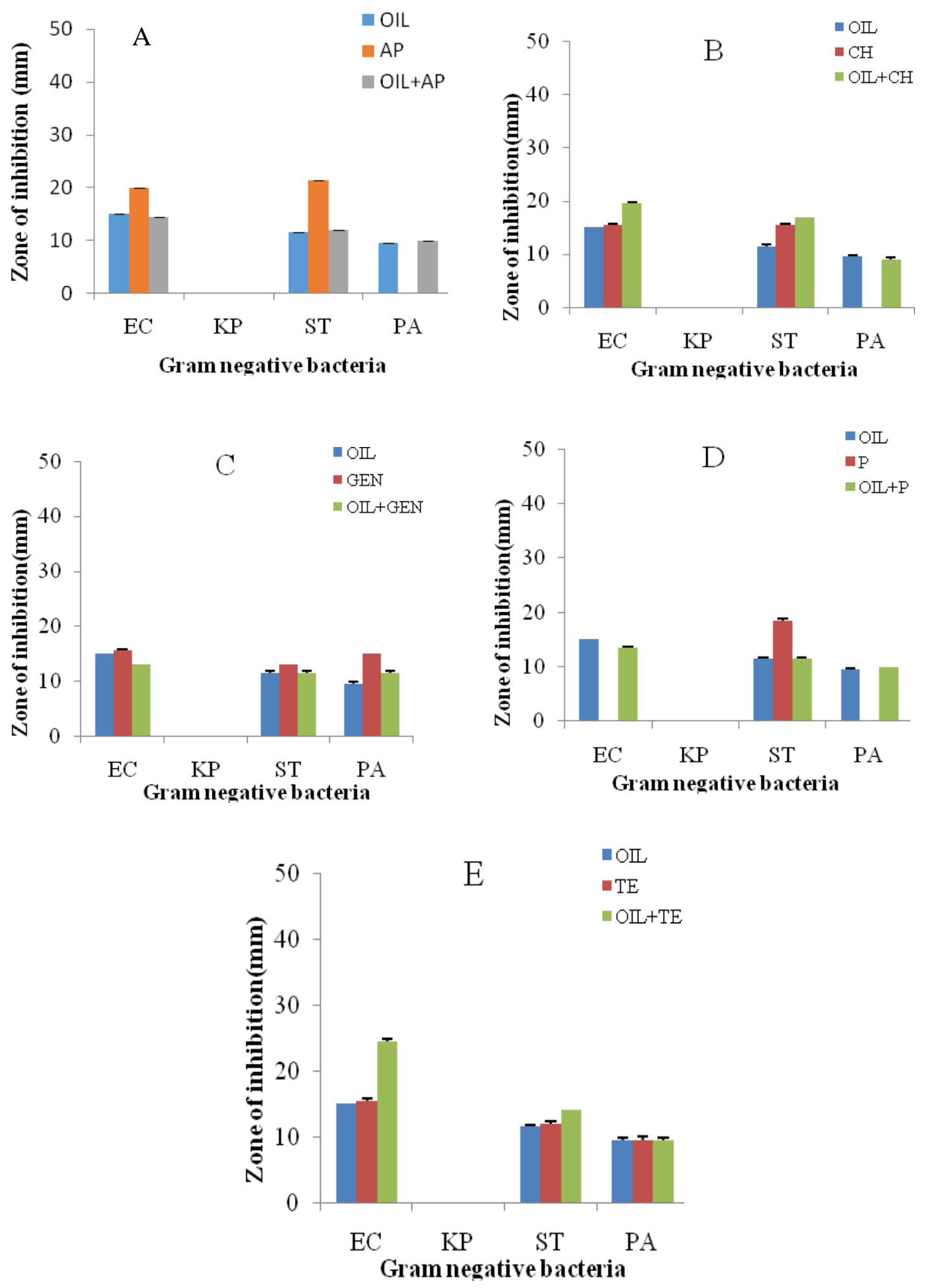
Fig.3 Synergistic antifungal activity of cinnamon oil with antibiotics against Fungi $(A=$ Amphotericin, $\mathrm{B}=$ Clotrimazole, $\mathrm{C}=$ Fluconazole, $\mathrm{D}=$ Itraconazole, $\mathrm{E}=$ Ketoconazole, $\mathrm{F}=$ Nystatin)
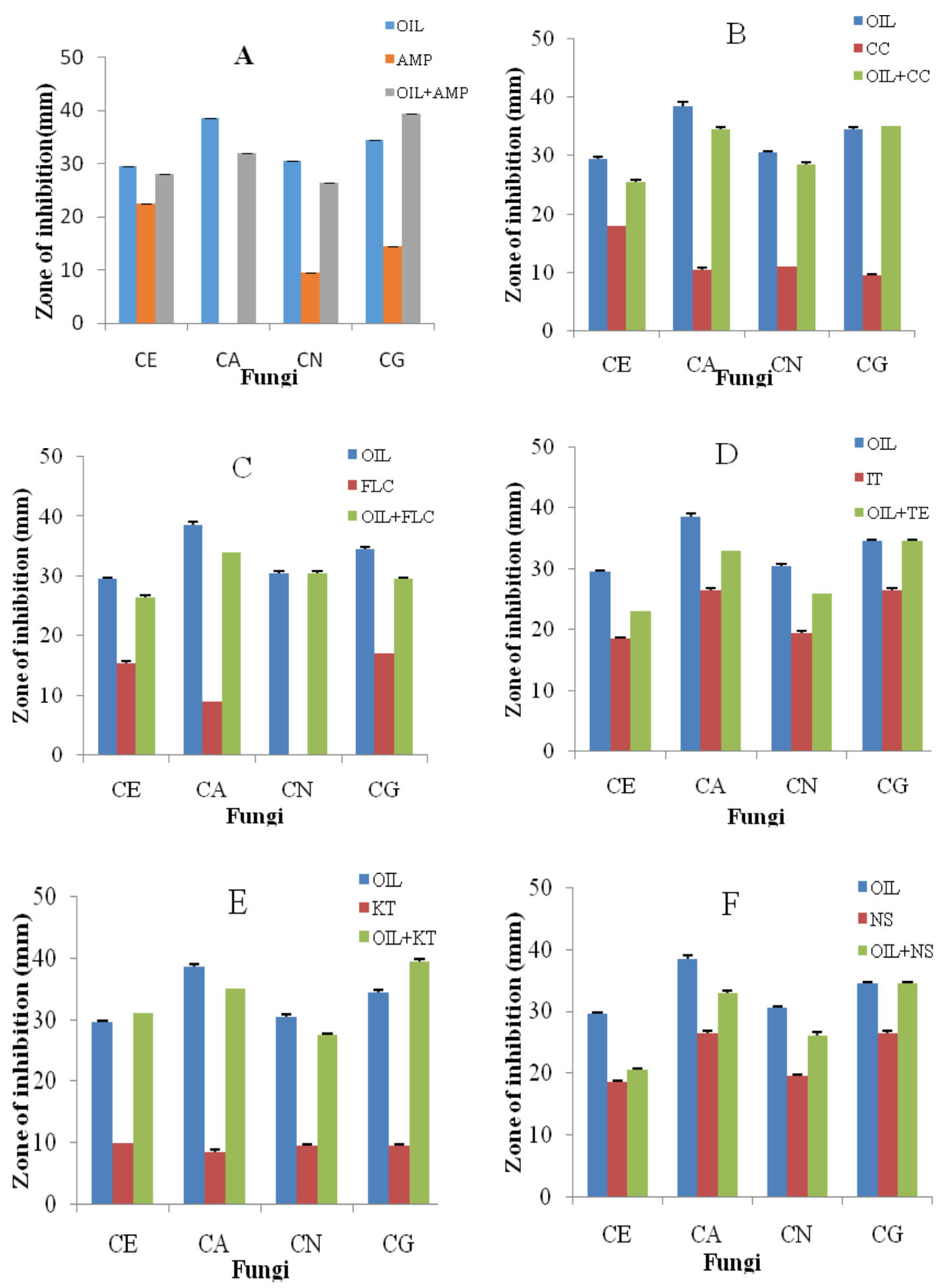
Fig.4 Synergistic antibacterial activity of cinnamon oil with other oil against Gram positive bacteria ( $\mathrm{A}=$ Clove oil, $\mathrm{B}=$ Karanja oil, $\mathrm{C}=$ Lemon oil, $\mathrm{D}=$ Orange oil, $\mathrm{E}=$ Neem oil $)$
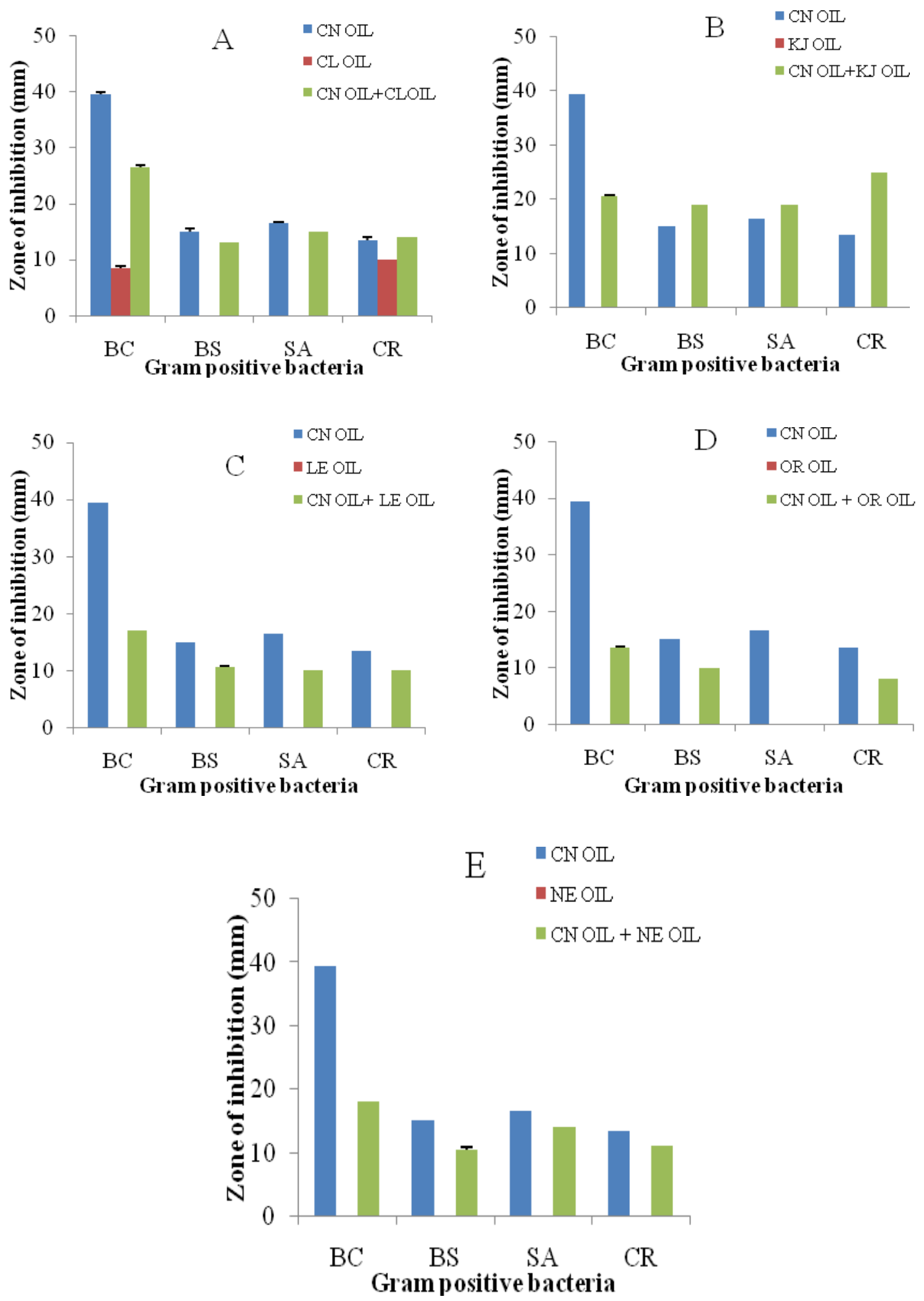
Fig.5 Synergistic antibacterial activity of cinnamon oil with other oil against Gram negative bacteria ( $\mathrm{A}=$ Clove oil, $\mathrm{B}=$ Karanja oil, $\mathrm{C}=$ Lemon oil, $\mathrm{D}=$ Orange oil, $\mathrm{E}=$ Neem oil)
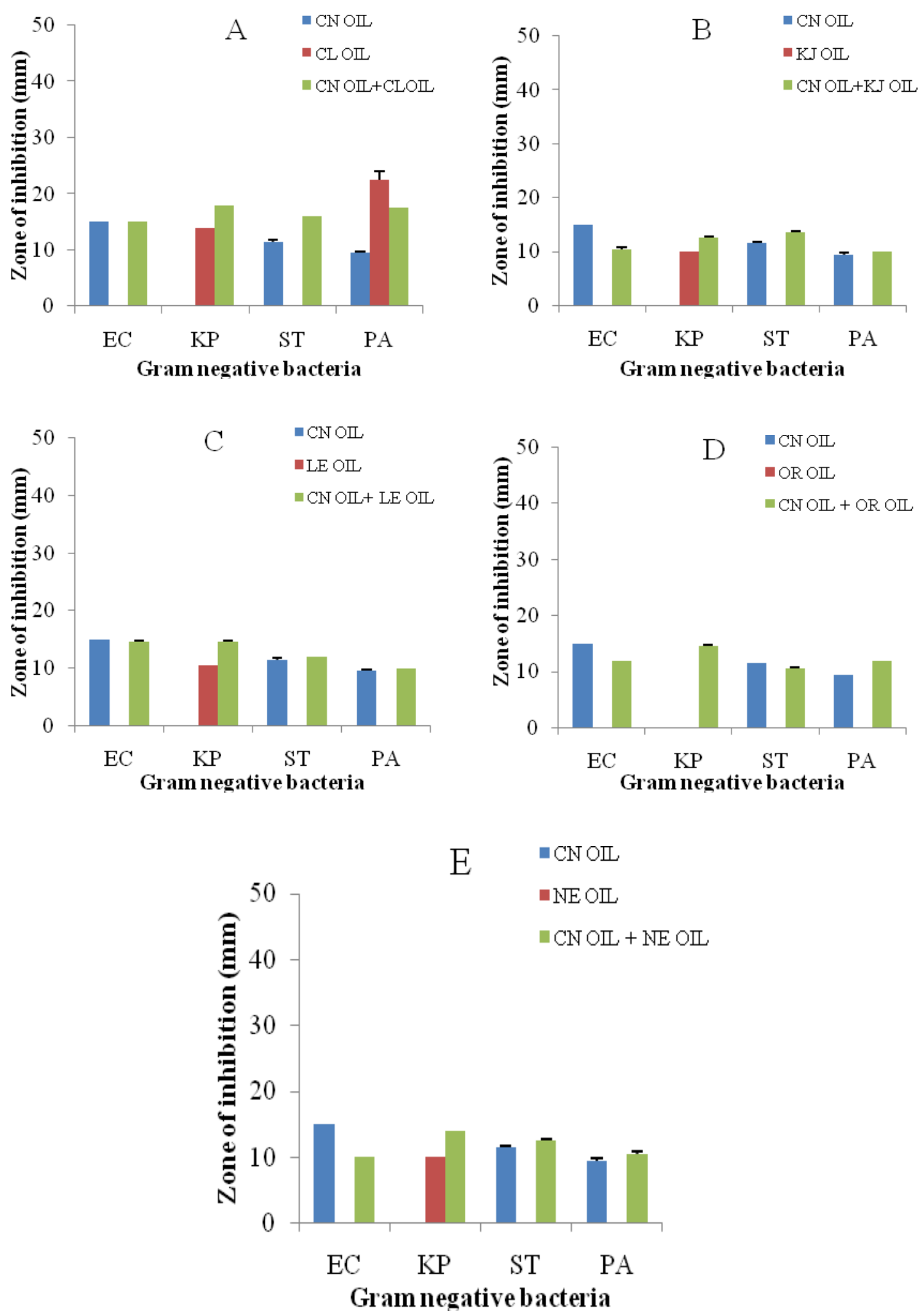
Fig.6 Synergistic antifungal activity of cinnamon oil with other oil against Fungi (A= Clove oil, $\mathrm{B}=$ Karanja oil, $\mathrm{C}=$ Lemon oil, $\mathrm{D}=$ Orange oil, $\mathrm{E}=$ Neem oil $)$
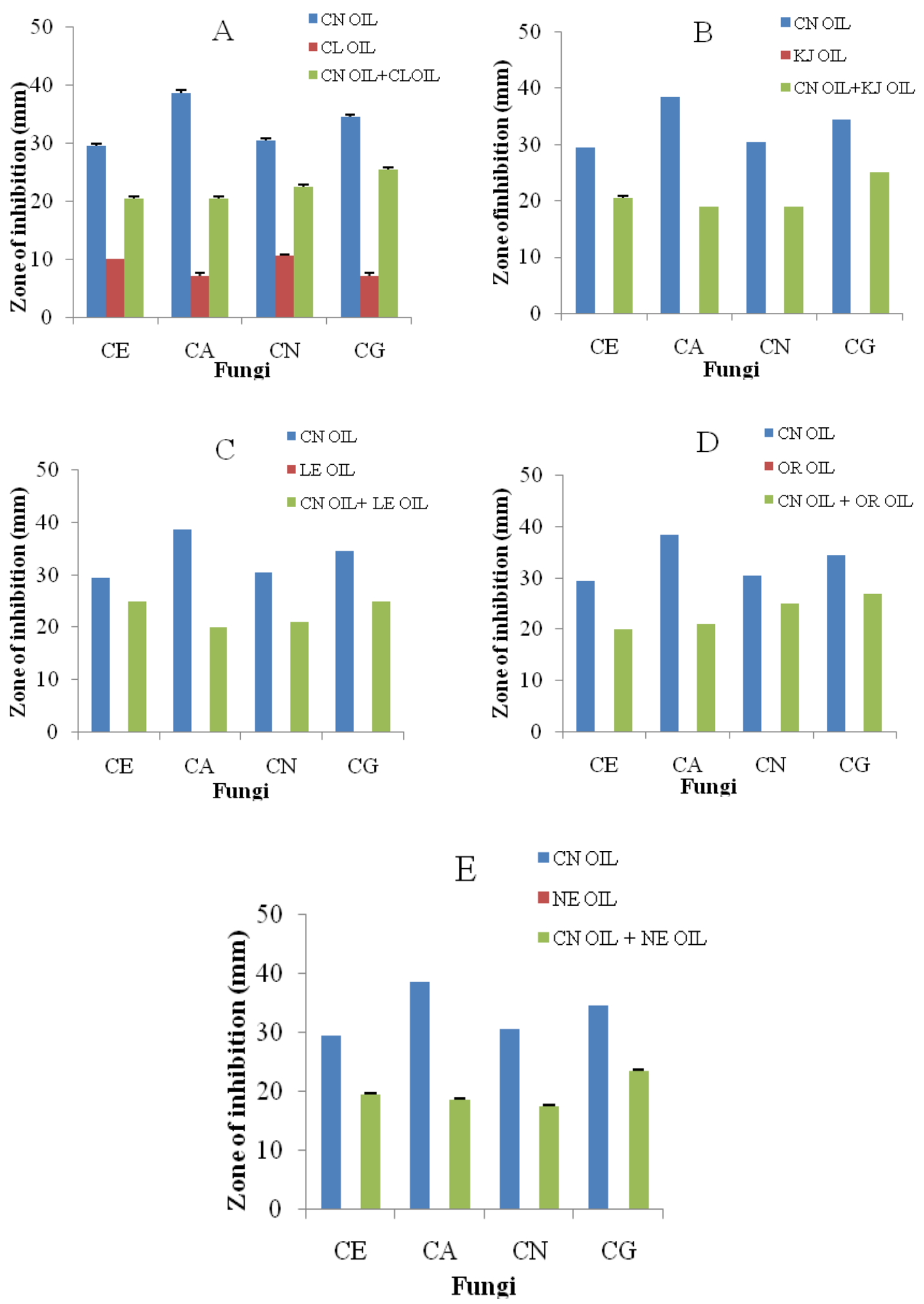
Table.1 MIC and MBC values of antibiotics/essential oil against Gram positive and negative bacteria

\begin{tabular}{ccccccccc}
\hline & \multicolumn{7}{c}{ Organisms } & \multicolumn{2}{c}{ EC } & \multicolumn{2}{c}{ PA } \\
\hline \multirow{2}{*}{ Antibiotics/Oils } & \multicolumn{2}{c}{ CR } & \multicolumn{2}{c}{ BS } & MIC & MBC & MIC & MBC \\
\cline { 2 - 9 } Ampicillin & 4 & 16 & 32 & $>32$ & 32 & $>32$ & $>32$ & $>32$ \\
\hline Chloramphenicol & 32 & $>32$ & 16 & 32 & 16 & 32 & 8 & 16 \\
\hline Gentamicin & 1 & 32 & 1 & 16 & 2 & 8 & 1 & 8 \\
\hline Penicillin & 1 & 16 & 32 & $>32$ & $>32$ & $>32$ & $>32$ & $>32$ \\
\hline Tetracycline & 2 & 4 & 1 & 8 & 2 & 4 & 1 & 4 \\
\hline Cinnamon oil & 100 & 100 & 200 & $>200$ & 25 & $>200$ & 12.5 & $>200$ \\
\hline Clove oil & 50 & $>200$ & 12.5 & 50 & 12.5 & $>200$ & 25 & $>200$ \\
\hline Orange oil & 25 & $>200$ & 25 & 100 & 12.5 & $>100$ & 12.5 & 100 \\
\hline Lemon oil & 25 & 50 & 12.5 & 100 & 25 & $>200$ & 6.25 & $>200$ \\
\hline Karanj oil & 12.5 & 100 & 50 & $>200$ & 100 & $>200$ & 25 & $>200$ \\
\hline Neem oil & 100 & $>200$ & 50 & $>200$ & 200 & $>200$ & 100 & 100 \\
\hline
\end{tabular}

Table.2 MIC and MBC values of antibiotics/essential oil against fungi

\begin{tabular}{ccccc}
\hline & \multicolumn{3}{c}{ Fungi } \\
\hline \multirow{2}{*}{ Antibiotics/Oils } & MIC & MBC & MIC & MBC \\
\cline { 2 - 5 } Amphotericin & $>32$ & $>32$ & $>32$ & $>32$ \\
\hline Fluconazole & 8 & $>32$ & 2 & $>32$ \\
\hline Ketoconazole & $>32$ & $>32$ & $>32$ & $>32$ \\
\hline Nystatin & 32 & $>32$ & $>32$ & $>32$ \\
\hline Cinnamon oil & 50 & $>200$ & 100 & $>200$ \\
\hline Clove oil & 6.25 & $>200$ & 12.5 & $>200$ \\
\hline Orange oil & 100 & $>200$ & 100 & $>200$ \\
\hline Lemon oil & 6.25 & $>200$ & 6.25 & $>200$ \\
\hline Karanj oil & 25 & $>200$ & 25 & $>200$ \\
\hline Neem oil & 100 & $>200$ & $>200$ & $>200$
\end{tabular}


Table.3 (A) MIC and MBC values for the combination of cinnamon oil with antibiotic and other essential oils against Gram positive bacteria

\section{Organisms}

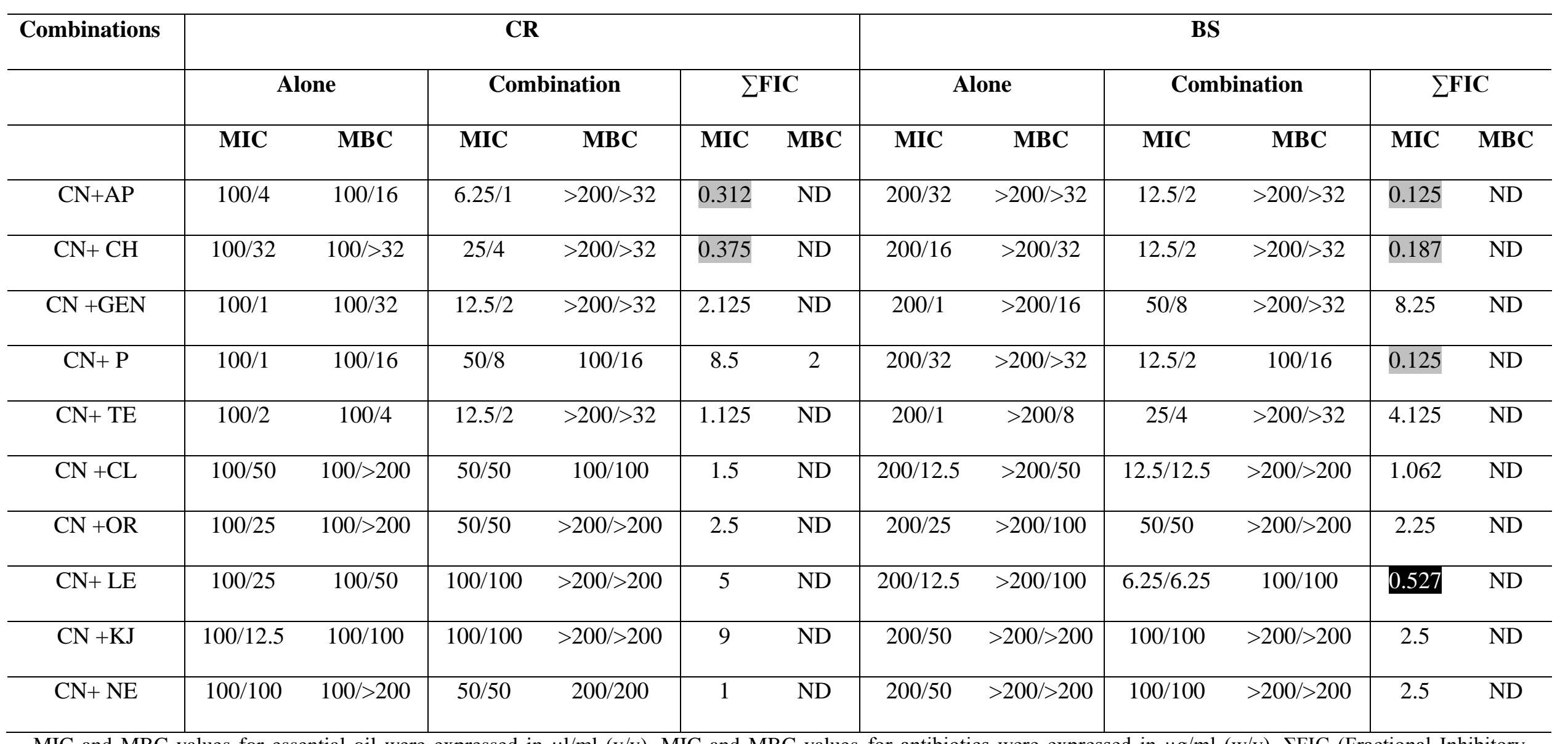

MIC and MBC values for essential oil were expressed in $\mu \mathrm{l} / \mathrm{ml}(\mathrm{v} / \mathrm{v})$. MIC and MBC values for antibiotics were expressed in $\mu \mathrm{g} / \mathrm{ml}$ (w/v). $\Sigma$ FIC (Fractional Inhibitory Concentration Index $)=\mathrm{FIC}_{\mathrm{A}}+\mathrm{FIC}_{\mathrm{B}} ; \mathrm{FIC}_{\mathrm{A}}=\left(\mathrm{MIC}_{\mathrm{A}}\right.$ combination $/ \mathrm{MIC}_{\mathrm{A}}$ alone $) ; \mathrm{FIC}_{\mathrm{B}}=\left(\mathrm{MIC}_{\mathrm{B}}\right.$ combination $/ \mathrm{MIC} \mathrm{B}_{\mathrm{B}}$ alone $)$; Results interpreted as follows : $\leq 0.5$ was assigned as a synergistic effect, $0.5>\sum F I C \leq 0.75$ represented as a partial synergy, 0.76 to 1.0 represented as an additive effect, $>1.0$ to 4.0 represented as an indifferent effect and $\sum$ FIC $>4.0$ antagonistic effect ND = Not determined because of high MIC value 
Table.3 (B) MIC and MBC values for the combination of cinnamon oil with antibiotic and other essential oils against Gram negative bacteria

\section{Organisms}

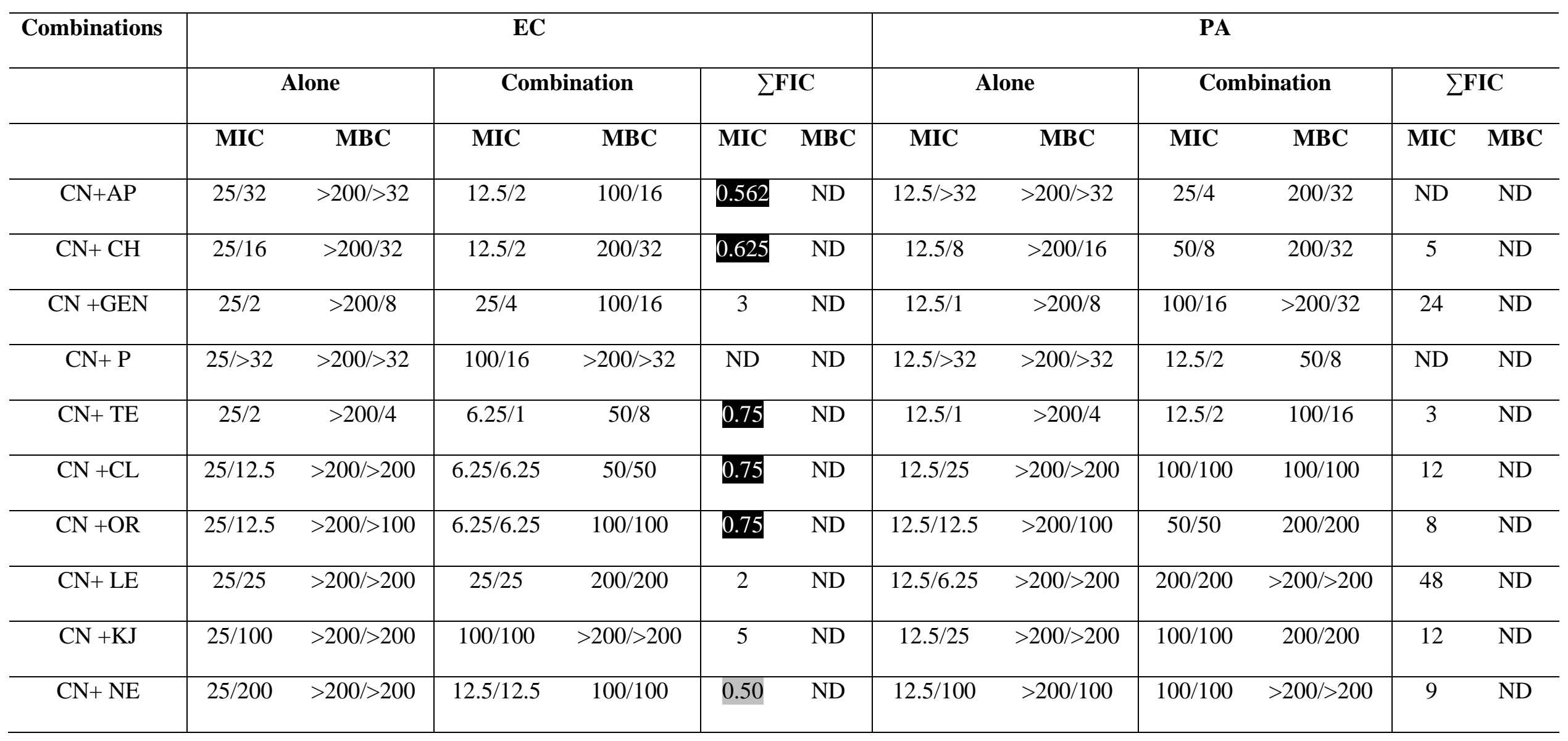

MIC and MBC values for essential oil were expressed in $\mu 1 / \mathrm{ml}(\mathrm{v} / \mathrm{v})$. MIC and MBC values for antibiotics were expressed in $\mu \mathrm{g} / \mathrm{ml}$ (w/v). $\Sigma$ FIC (Fractional Inhibitory Concentration Index $)=\mathrm{FIC}_{\mathrm{A}}+\mathrm{FIC}_{\mathrm{B}}$; $\mathrm{FIC}_{\mathrm{A}}=\left(\mathrm{MIC}_{\mathrm{A}}\right.$ combination $/ \mathrm{MIC}_{\mathrm{A}}$ alone $) ; \mathrm{FIC}_{\mathrm{B}}=\left(\mathrm{MIC}_{\mathrm{B}}\right.$ combination $/ \mathrm{MIC}$ alone $)$; Results interpreted as follows : $\leq 0.5$ was assigned as a synergistic effect, $0.5>\sum \mathrm{FIC} \leq 0.75$ represented as a partial synergy, 0.76 to 1.0 represented as an additive effect, $>1.0$ to 4.0 represented as an indifferent effect and $\sum$ FIC $>4.0$ antagonistic effect ND $=$ Not determined because of high MIC value 
Table.3 (C) MIC and MBC values for the combination of cinnamon oil with antibiotic and other essential oils against Fungi.

\section{Organisms}

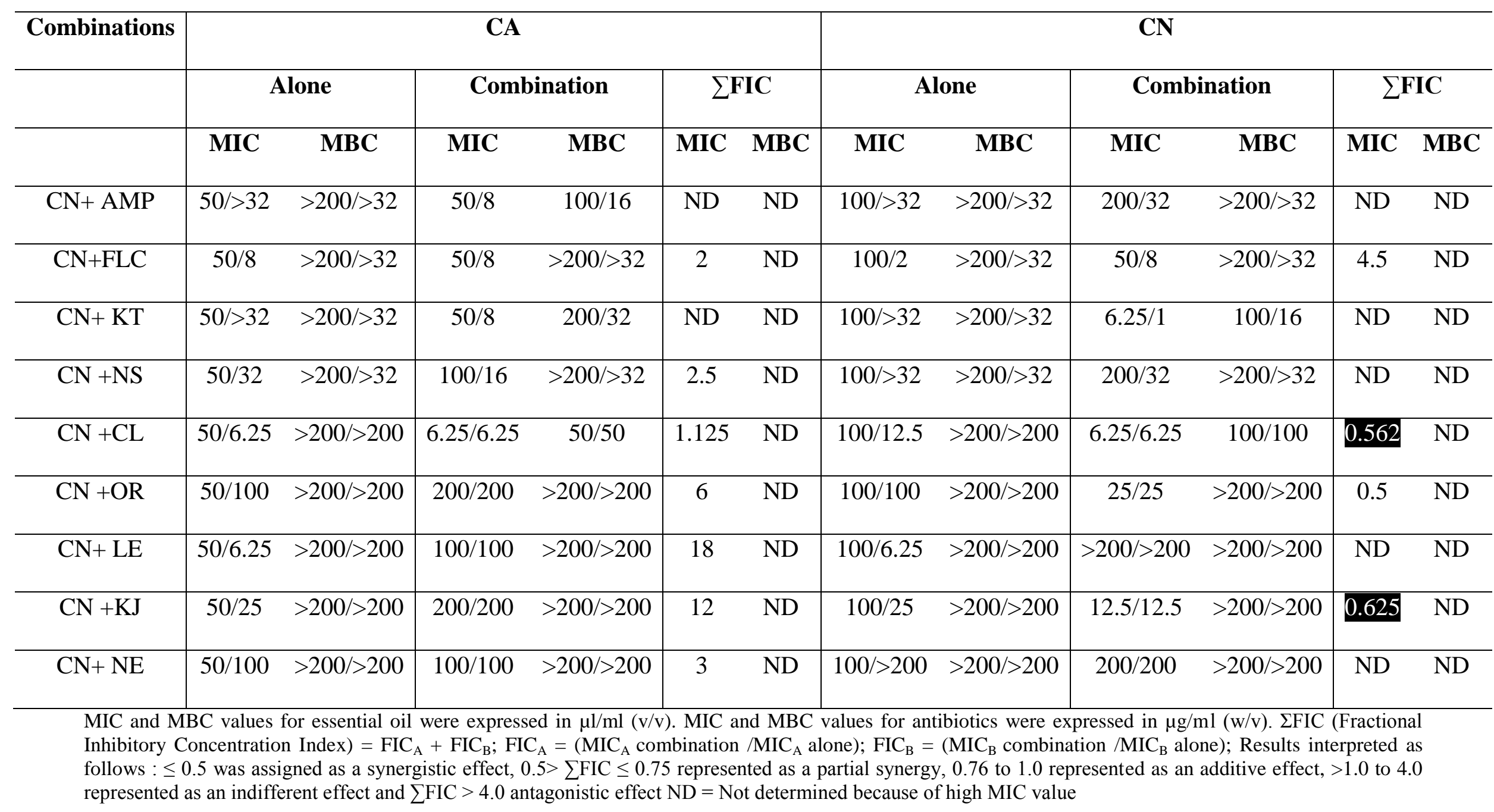


For Gram negative bacteria strains, MIC and $\mathrm{MBC}$ values of all five antibiotic ranged from 1 to $>32 \mu \mathrm{g} / \mathrm{ml}$ and 4 to $>32 \mu \mathrm{g} / \mathrm{ml}$ respectively. $P$. aeruginosa was most susceptible bacterial pathogen to GEN and TE (MIC- $1 \mu \mathrm{g} / \mathrm{ml}$ ). The MIC and MBC value of all six essential oil ranged from 6.25 to 200 $\mu \mathrm{l} / \mathrm{ml}$ and 100 to $>200 \mu \mathrm{l} / \mathrm{ml}$ respectively. $P$. aeruginosa was most susceptible bacterial pathogen to $\mathrm{LE}$ oil (MIC $-6.25 \mu \mathrm{l} / \mathrm{ml}$ ).

For fungal strains, MIC and $\mathrm{MBC}$ values of all six antibiotic ranged from 2 to $>32 \mu \mathrm{g} / \mathrm{ml}$ and $>32 \mu \mathrm{g} / \mathrm{ml}$ respectively. C. neoformans was most susceptible fungal pathogen to FLC (MIC- $2 \mu \mathrm{g} / \mathrm{ml}$ ). The MIC and MBC values of all six essential oil ranged from 6.25 to $>200$ $\mu \mathrm{l} / \mathrm{ml}$ and $>200 \mu \mathrm{l} / \mathrm{ml}$ respectively. CL and KR oil effectively inhibit both the fungi (MIC $-6.25 \mu \mathrm{l} / \mathrm{ml})$.

Amongst the tested microbial strains $C$. neoformans, C. albicans, $P$. aeruginosa was inhibited by LE oil with list MIC values 6.25 $\mu 1 / \mathrm{ml}$. Its $\mathrm{MBC}$ values were $>200 \mu \mathrm{l} / \mathrm{ml}$. While amongst six essential oils CL and LE oil showed good antimicrobial activity followed by OR oil against bacteria and fungi.

\section{Synergistic antimicrobial activity of cinnamon oil}

Synergistic antimicrobial activity of cinnamon oil with antibiotic and other essential oil were evaluated against two Gram positive, two Gram negative and two fungi. Synergistic effect was determined by calculation FIC index. Results are interpreted as follows: $\leq 0.5=$ synergistic; $>0.5$ to $0.75=$ partially synergistic; 0.76 to $1.0=$ additive; $>1.0$ to $4.0=$ indifferent and $>4.0=$ antagonistic; ND = Note determined because of high MIC value $>32 \mu \mathrm{g} / \mathrm{ml}$ and $>200 \mu \mathrm{l} / \mathrm{ml}$.

Synergistic antibacterial activity of cinnamon oil against Gram positive bacteria is summarized in the Table 3(A). The FIC indices of combination of $\mathrm{CN}$ oil ranged from 0.312 to 2.125 against $C$. rubrum and 0.125 to 8.25 against $B$. subtilis. The combination of $\mathrm{CN}+\mathrm{AP}$ and $\mathrm{CN}+\mathrm{CH}$ showed synergistic antibacterial activity against $C$. rubrum and $B$. subtilis. Combination of $\mathrm{CN}+\mathrm{P}$ and $\mathrm{CN}+\mathrm{LE}$ showed synergistic and partial synergies antibacterial activity against $B$. subtilis with FIC indices 0.125 and 0.527 respectively. The remaining combination showed additive / indifferent/antagonistic effect against $C$. rubrum and $B$. subtilis.

Synergistic antibacterial activity of cinnamon oil against Gram negative bacteria is summarized in Table 3(B). The FIC indices of combination of $\mathrm{CN}$ oil ranged from 0.50 to 5 against $E$. coli and 3 to 48 against $P$. aeruginosa. The combinations of $\mathrm{CN}+\mathrm{NE}$ showed synergistic antibacterial activity against $E$. coli with FIC indices was 0.50 . The combinations of $\mathrm{CN}+\mathrm{AP}, \mathrm{CN}+\mathrm{TE}, \mathrm{CN}+\mathrm{CH}$, $\mathrm{CN}+\mathrm{CL}$ and $\mathrm{CN}+\mathrm{OR}$ showed partial synergistic antibacterial activity against $E$. coli. Remaining combination showed additive / indifferent /antagonistic effect against $E$. coli. None of the combination showed synergistic antibacterial activity against $P$. aeruginosa.

Synergistic antifungal activity of cinnamon oil against fungi is summarized in Table 3(C). The FIC indices of combination of $\mathrm{CN}$ oil ranged from 1.124 to 18 against $C$. albicans and 0.562 to 4.5 against $C$. neoformans.

The combination of $\mathrm{CN}+\mathrm{CL}$ and $\mathrm{CN}+\mathrm{KJ}$ showed partial synergistic antifungal activity against fungi $C$. neoformans with FIC indices 0.562 to 0.625 respectively.

The remaining combinations showed additive/indifferent/antagonistic effect against $C$. neoformans. None of the combinations showed synergistic antifungal activity. 
Comparison of $\mathrm{CN}$ oil combinations with antibiotic/other essential oils, combination of $\mathrm{CN}$ oil with antibiotics showed better synergistic antimicrobial activity as compared to $\mathrm{CN}$ oil with other essential oils. Combination of $\mathrm{CN}$ oil with $\mathrm{AP}$ and $\mathrm{CH}$ antibiotic showed best synergistic antibacterial activity against $C$. rubrum, $B$. subtilis and partial synergistic activity against E. coli. Luis et al., (2016) also reported synergistic antibacterial activity of two essential oils Eucalyptus globulus and Eucalyptus radiate with conventional antibiotic against Acinetobacter baumannii. Silva et al., (2011) also found synergistic antifungal activity of Coriandrum sativum essential oil with amphotericin B against Candida tropicalis and Candida albicans.

Combination of $\mathrm{CN}$ oil with $\mathrm{NE}$ oil showed synergistic activity against $E$. coli while Combination of $\mathrm{CN}$ oil with $\mathrm{CL}$ and $\mathrm{KJ}$ oil showed partial synergistic activity against $C$. neoformans. Matam et al., (2006) analyzed that mixture of cinnamon and clove essential oils showed synergistic antimicrobial activity against food spoilage microorganisms. Similar results are reported by Pekmezovic et al., (2015). According to them Thymus vulgaris and Cinnamomum cassia essential oil combination showed synergistic antifungal activity. C. rubrum and E. coil were the most susceptible bacterial pathogens.

Synergistic effect of natural product and conventional antimicrobial agents against infectious pathogen is growing field of herbal medicine (Wagner and Ulrich-Merzenich, 2009).

The increase in synergistic antimicrobial effect may be caused by the reaction between essential oil and antibiotics or other essential oil. The cinnamon oil contains major bioactive components Cinnamaldehyde which can synchronize easily with antibiotic and other essential oil functional group and exert synergistic antimicrobial activity. It has been previously reported that cinnamaldehyde was able to inhibit the synthesis of essential enzyme of microorganisms and resulted in the damage and cell death of the microorganisms (Helander et al., 1998; Di Pasqua et al., 2007). There for it the observed synergistic antimicrobial activity of cinnamon oil may be due to the various compounds presentin the oil especially cinnamaldehyde.

The present findings showed that most of the tested essential oil combinations inhibited in vitro microbial growth with different degree depending on the type of oil or antibiotic, microorganism, concentration etc. Among the different combination of $\mathrm{CN}$ oil, $\mathrm{CN}$ oil with antibiotic $\mathrm{AP}$ and $\mathrm{CN}$ oil with $\mathrm{CL}$ oil was found to be the most effective. This essential oil combination i.e. $\mathrm{CN}$ oil plus $\mathrm{AP}$ and $\mathrm{CN}$ oil plus CL oil can be used as new treatment modalities to treat the bacterial infections. This combination may reduce antibiotic minimum effective dose and thus can minimize potential antibiotic side effects and prevent the emergence of antibiotic resistance.

Combination of cinnamon oil with antibiotic and other essential oil exhibited stronger antimicrobial properties against pathogens by disc diffusion method and broth dilution method (MIC).

In addition, combination also showed partial synergistic and additive effect can also be beneficial for development of novel antimicrobial agents. Among the different combinations, Cinnamon oil with ampicillin and Cinnamon oil with Clove oil showed good antimicrobial activity against pathogenic microorganisms even at low MIC value. However more studies are needed to understand the mechanism of action responsible for antimicrobial activity. 


\section{Acknowledgements}

The authors thank Department of Biosciences (UGC-CAS) for providing excellent research facilities. The authors HP, TR and PM are thankful to UGC, New Delhi, India for providing Junior Research Fellowship.

\section{References}

Akinyemi KO, Oladapo O, Okwara CE, Ibe CC and Fasure KA (2005). Screening of crudeextracts of six medicinal plants used in South-West Nigerian unorthodox medicine for anti-methicillin resistant Staphylococcus aureusactivity. BMC Complimentary and Alternative Medicine. 5:6-12.

Akthar MS, Degaga B and Azam T (2014). Antimicrobial activity of essential oils extracted from medicinal plants against the pathogenic microorganisms: A review. Issues in Biological Sciences and Pharmaceutical Research. 2(1):1-7.

Bakkali F, Averbeck S, Averbeck D and Idaomar M (2008).Biological effects of essential oils - A review.Food and Chemical Toxicology. 46(2):446-475.

Clemente I, Aznar M, Silva F, Nerin C (2016) Antimicrobial properties and mode of action of mustard and cinnamon essential oils and their combination against foodborne bacteria. Innovative Food Science and Emerging Technologies 36:2633.

Di Pasqua R, Betts G, Hoskins N, Edwards M, Ercolini D, Mauriello G (2007). Membrane toxicity of antimicrobial compounds from essential oils. Journal of Agricultural and Food Chemistry. 55(12):4863-4870

Dorman HJD and Deans SG (2000) Antimicrobial agents from plants: antibacterial activity of plant volatile oils. Journal of Applied Microbiology 88:308-316.

Edziria h, Ammarc S, Souadc L, Mahjoubc MA, Mastourib M, Aounia M, Mighric Z and Verschaeved L (2012). In vitro evaluation of antimicrobial and antioxidant activities of some Tunisian vegetables. South African Journal of Botany. 78:252-256.
European Committee for Antimicrobial Susceptibility Testing (EUCAST) (2003).Determination of minimum inhibitory concentrations (MICs) of antibacterial agents by broth dilution. Clinical Journal of Microbiology Infection. 9:1-7.

Frey M and Meyers R (2011).Antibacterial activity of traditional medicinal plants used by Haudenosaunee peoples of New York State. BMC Complimentary AlternativeMedicine. 10:64-68.

Gendy AME, Leonardi M, Mugnainic L, Bertelloni F, Ebanic VV, Nardoni S, Mancianti F, Hendawy S, Omera E, Pistelli L(2015) Chemical composition and antimicrobial activity of essential oil of wild and cultivated Origanum syriacum plants grown in Sinai, Egypt. Industrial Crops and Products 67: 201-207.

Ghabraie M, Vu KD, Tata L, Salmieri S, Lacroix M (2016) Antimicrobial effect of essential oils in combinations against five bacteria and their effect on sensorial quality of ground meat. Food Science and Technology. 66:332-339.

Giordani R, Regli P, Kaloutian J, Mikali C, Abou L, Portugal H (2005) Antifungal effect of various essential oils against Candida albicans. Potentiation of antifungal action of amphotericin B by essential oil from Thymus vulgaris. Phytotherapy Research. 18(12):990-995.

Helander IM, Alakomi HL, Latva-Kala K, Mattila-Sandholm T, Pol I, Smid EJ, Gorris LGM, von Wright A (1998). Characterization of the action of selected essential oil components on gram-negative bacteria. Journal of Agricultural and Food Chemistry. 46(9):3590-3595.

Huttner A, Harbarth S, Carlet J, Cosgrove S, Goossens H, Holmes A (2013) Antimicrobial resistance: a global view from the 2013 world healthcare-associated infections forum. Antimicrobial Resistance and Infection Control. 2: 1-13.

Ibrahim L, Karaky M, Ayoub P, Ajouz NE, Ibrahim S(2012). Chemical composition and antimicrobial activities of essential oil and its components from Lebanese Origanum syriacum L. Journal of Essential 
Oil Research 24 (4):339-345.

Luis A, Duarte A, Gominho J, Domingues F, Duartea AP (2016) Chemical composition, antioxidant, antibacterial and antiquorumsensing activities of Eucalyptus globulus and Eucalyptus radiate essential oils. Industrial Crops and Products 79:274-282.

Matan N, Rimkeeree H, Mawson AJ, Chompreeda P, Haruthaithanasan V and ParkerM (2006). Antimicrobial activity of cinnamon and clove oils under modified atmosphere conditions. International Journal of Food Microbiology. 107(2):180-185.

Nakhuru KS, Pfoze NL, Goswami S, Gogoi HK (2013) Investigation of the antimicrobial activity of crude alkaloids extract of Dicentra scandens (D. DON) WALP. tuberous root. Journal of Experimental Biology and Agricultural Sciences. 1(2S):102-105.

Padalia H and Chanda S (2015) Comparative pytochemical analysis of aerial parts of $A$. procumbeans, $F$. dichotoma, S. spontenem, $S$. nigra and $T$. angustifolia. Journal of Pharmacognosy and Phytochemistry 4(2):11-16

Pekmezovic M, Rajkovic K, Baraca A, Senerovic $\mathrm{L}$ and Arsenijevica AV (2015).Development of kinetic model for testing antifungal effect of Thymus vulgaris L. and Cinnamomum cassia L. essential oils on Aspergillus flavus spores and application for optimization of synergistic effect. Biochemical Engineering Journal. 99:131137.

Pintoa E, Goncalves MJ s Hrimpenga K, Pintoa J, Vaza S, Silva LAV, Cavaleiro C, Salgueiroba L (2013) Antifungal activity of the essential oil of Thymus villosus subsp. lusitanicus against Candida, Cryptococcus, Aspergillus and dermatophyte species. Industrial Crops and Products. 51 (2013) 93-99

Prabuseenivasan S, Jayakumar $\mathrm{M}$ and Ignacimuthu $S$ (2006).In vitro antibacterial activity of some plant essential oils. BMC Complementary and Alternative Medicine.6(39):1-8.

Rakholiya K and Chanda S (2012).In vitro interaction of certain antimicrobial agent in combination with plant extracts against some pathogenic bacterial strains. Asian Pacific Journal of Tropical Biomedicine. S876-S880.

Sabate DC, Ganzalea MJ, Porrini MP, Eguaras MJ, Audisio MC, Marioli JM (2012) Synergistic effect of surfactin from Bacillus subtilis $\mathrm{C} 4$ and Achyrocline satureioides extracts on the viability of Paenibacillus larve. World Journal of Microbiology and Biotechnology. 28:1415-1422.

Silva F, Ferreira S, Duarte A, Mendon DI and Domingues FC (2011).Antifungal activity of Coriandrum sativum essential oil, its mode of action against Candida species and potential synergism with amphotericin B. Phytomedicine.19:42-47.

Singh M, Khatoon S, Singh S, Kumar V, Rawat AK and Mehrotra S (2010). Antimicrobial screening of ethanobotanically importance stem bark of medicinal plants. Pharmacognosy Research. 2:254-257.

Wagner H and Ulrich-Merzenich G (2009). Synergy research: approaching a new generation of phytopharmaceuticals. Phytomedicine 16, 97-110.

\section{How to cite this article:}

Hemali Padalia, Tejas Rathod, Pooja Moteriya and Sumitra Chanda. 2017. Antimicrobial Efficacy of Cinnamonum verum Essential Oil Alone and in Combination with Antibiotics and Other Essential Oils. Int.J.Curr.Microbiol.App.Sci. 6(11): 3377-3395.

doi: https://doi.org/10.20546/ijcmas.2017.611.397 